ZANUNCIO, Sharinna Venturim; MAFRA, Simone Caldas Tavares; FRANÇA, Lúcia Helena de Freitas Pinho; FERREIRA, Pedro Maria da Cunha Moura. Por que continuar trabalhando na velhice? O caso de Hefesto e seus 95 anos. Oikos: Família e Sociedade em Debate, v. 30, n. 1, p. 104-127, 2019.

\section{PPGED}

Programa de Pós-Graduaçoso am Ecanamia Damestice.

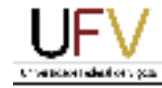

DOI: https://doi.org/10.31423/oikos.v30i1.3813

www.periodicos.ufv.br/oikos | ISSN: 2236-8493 revistaoikos@ufv.br
Avaliação: Double Blind Review Recebido: 10/12/2018 Aprovado: 18/02/2019

\title{
Por que continuar trabalhando na velhice? 0 caso de Hefesto e seus 95 anos $^{1}$
}

\author{
Why continue to work in the old age? The case of Hefesto and its 95 years
}

\author{
Sharinna Venturim Zanuncio ${ }^{2}$ \\ Simone Caldas Tavares Mafra ${ }^{3}$ \\ Lúcia Helena de Freitas Pinho França ${ }^{4}$ \\ Pedro Maria da Cunha Moura Ferreira ${ }^{5}$
}

\begin{abstract}
Resumo
Objetivou-se conhecer e analisar a história de vida laboral de uma pessoa idosa de 95 anos, que ainda se encontra ativa no mercado de trabalho formal, desenvolvendo a mesma atividade, pelas IES que passou, sejam elas públicas ou privada. Para alcance deste foi utilizado o método de história de vida, guiado por entrevista semiestruturada, junto ao sujeito participante, escolhido intencionalmente pelas pesquisadoras, devido a sua trajetória no mercado laboral. Histórias como esta, permite uma maior conscientização, de que o envelhecimento é uma conquista significativa, quando se foca na ampliação da capacidade da pessoa idosa em contribuir com a sociedade e garantir a empregabilidade do trabalhador maduro (a partir de 50 anos), em condições de igualdade de oportunidades e de recursos. Pois, histórias como essa, deixarão de ser exceção e passarão a ser cada vez mais frequentes, devido ao processo de envelhecimento da população e sua permanência no mercado de trabalho, por um período mais longo. Sendo necessário, refletir acerca da valorização da pessoa idosa no meio social, um desafio que requer respostas urgentes, pois como observado nesta pesquisa, os fatores que as motivam a permanecer no trabalho estão relacionados principalmente, à manutenção da vida e saúde mental, social e econômica, recebendo reconhecimento no ambiente profissional, familiar, assim como a valorização da sociedade, fazendo-os inseridos no contexto social, sentindo-se úteis e capazes, superando o estigma de que a velhice seja a etapa da vida relacionada ao processo de finitude e inutilidade.
\end{abstract}

\begin{abstract}
The objective was to know and analyze the labor history of a 95-year-old elderly person, who is still active in the formal labor market, developing the same activity, by the HEI that has passed, whether public or private. To achieve this, the life history method, guided by a semi-structured interview, was used with the participant subject, intentionally chosen by the researchers, due to their trajectory in the labor market. Stories such as this, allows for greater awareness that aging is a significant achievement when it focuses on expanding the elderly person's ability to contribute to society and ensure the employability of the mature worker (age 50 and older), under conditions equality of opportunity and resources. For such stories will cease to be an exception and will become increasingly frequent due to the process of aging of the population and its permanence in the labor market for a longer period. It is necessary, to reflect on the appreciation of the elderly in the social environment, a challenge that requires urgent answers, because as observed in this research, the factors that motivate them to stay in work are mainly related to the maintenance of life and mental, social and economic, and receiving recognition in the professional and family environment, as well as the valuation of society, making them inserted in the social context, feeling useful and capable, overcoming the stigma that old age is the stage of life related to the process of to the end of life process and uselessness.
\end{abstract}

\footnotetext{
${ }^{1}$ Parte da pesquisa de tese realizada durante o curso de Doutorado do Programa de Pós-Graduação em Economia Doméstica da Universidade Federal de Viçosa, Viçosa/MG, com o apoio da CAPES.

2 Doutoranda em Economia Doméstica pelo Programa de Pós-graduação em Economia Doméstica da Universidade Federal de Viçosa. E-mail: sharinnavz@yahoo.com.br

3 Doutora em Engenharia de Produção, Professora da Universidade Federal de Viçosa, Viçosa, MG. E-mail: sctmafra@ufv.br ${ }^{4}$ PhD. em Psicologia, Docente Permanente do Programa de Pós-Graduação em Psicologia da Universidade Salgado de Oliveira (UNIVERSO). E-mail: luciafranca@luciafranca.com

5 Doutor em Psicologia, Investigador Auxiliar do Instituto de Ciências Sociais da Universidade de Lisboa. E-mail: pmferreira@ics.ulisboa.pt
} 
Palavras-chave: Pessoa Idosa; Envelhecimento Ativo; Key-words: Elderly; Active Aging; Ageism; Aging in the Labor Ageísmo; Envelhecimento no Mercado de Trabalho. Market 


\section{INTRODUÇÃO}

É possível perceber que avanços significativos foram alcançados no conhecimento sobre o processo de envelhecimento populacional não só mundial como também brasileiro. Em sua maioria, estes avanços consideram os aspectos relacionados à saúde, buscando sua interface com a melhoria da qualidade de vida deste extrato da população, objetivando não apenas a longevidade por si só, mas uma vida longeva com autonomia e independência.

O envelhecimento da população é fato em grande parte dos países desenvolvidos e em desenvolvimento, e, durante muito tempo, a realidade vivenciada pela maioria desses países, era de uma população jovem, onde a sobrevida era bem menor do que a de hoje. Além disso, a fase da velhice, por vezes, estava relacionada ao deterioramento do indivíduo e de suas capacidades, à chegada de doenças ou mesmo à espera da morte. Lidar com esse novo panorama e os impactos que ele traz, ainda é um desafio, tanto para as pessoas idosas, quanto para suas famílias, sociedade civil e Estado.

Uma população pode ser considerada como uma entidade coletiva, pertencente a um determinado ambiente, no qual o indivíduo se insere pelo nascimento ou imigração e sai pela morte ou emigração, depois de aí permanecer pelo transcorrer da vida ou duração do tempo de permanência como migrante (PEREIRA, 2005).

Neste contexto, pode-se reafirmar então que a transição demográfica está relacionada à mudança de um padrão caracterizado por elevadas taxas de mortalidade e fecundidade para outro contexto, em que essas taxas passam a ser significativamente mais baixas. Considera-se de fundamental importância identificar as alterações ocorridas no estilo de vida e na prevalência de fatores de risco, que também colaboraram nessa transição e, consequentemente, podem trazer mudanças e alterações à coletividade, como a permanência por mais tempo no mercado de trabalho por parte dos indivíduos, ou mesmo a sua reinserção após o processo de aposentadoria.

Entretanto, tal como a relação saúde e longevidade, outro aspecto que ganha importância nos estudos relacionados ao envelhecimento demográfico, diz respeito à relação dessa longevidade e o impacto por ela causado no sistema econômico dos países, principalmente, no que diz respeito ao fator previdenciário e à idade para a aposentadoria. No entanto, é preciso considerar que essa longevidade no mercado de trabalho, não está associada apenas às questões de saúde e economia, mas também, aos aspectos sociais e culturais do indivíduo e das organizações, uma vez que têm impacto direto no envelhecimento ativo destes atores sociais e em sua qualidade de vida e na de suas famílias. 
Assim, a necessidade de estudos e construção de políticas públicas e sociais, que busquem responder ao envelhecimento ativo no mercado de trabalho, não apenas direcionadas às pessoas idosas, mas a todos os indivíduos, independentemente de sua idade e percursos laborais, torna-se eminente. Parte fundamental desse processo é dar voz a esses trabalhadores mais velhos e que ainda continuam ativos no mercado de trabalho, principalmente o formal, identificando fatores que considerem fundamentais, no que diz respeito ao seu percurso laboral (ILC BRASIL, 2015, PINTO, 2015).

Como reafirma Wisner (1994), pode-se considerar o fenômeno do envelhecimento entre os 20 e 50 anos, em que geralmente ocorre aumento da probabilidade de redução das capacidades. Este aumento varia muito de um tipo de capacidade para outra, e de um indivíduo para outro. A idade não é um meio seguro de predição das capacidades de um indivíduo. Daí a importância do aprendizado ao longo da vida para os trabalhadores, proporcionando-Ihes oportunidades equitativas de formação, treinamento e capacitação, independentemente da idade em que estejam visando a valorização do capital humano como um todo nas organizações.

Outro avanço quanto aos estudos da relação envelhecimento e trabalho, é que esta tem sido explorada pelas mais diversas áreas de conhecimento, abrangendo as ciências sociais, da saúde e econômicas. O interesse de estudos quanto à essas questões vêm inicialmente, como mencionado, do envelhecimento populacional observado, mas também do desafio enfrentado pelas organizações, no que diz respeito à idade e ao conhecimento técnico de seus trabalhadores. Tais aspectos configuram na relação mercado de trabalho/pessoa idosa e as situações de ageísmo, ou seja, preconceito contra a pessoa idosa. Se, por um lado, têm-se jovens com alto nível de formação entrando no mercado de trabalho, por outro, se observa um grande número de trabalhadores mais velhos e com menor nível de formação, porém com grande experiência na execução de suas atividades (LAVILLE; VOLKOFF, 2007).

Fazem-se assim necessárias, práticas de gestão da idade (condutas que visam minimizar os efeitos do envelhecimento do profissional nas organizações e minimizar as barreiras etárias) estando ligadas ao processo de recrutamento, formação, desenvolvimento e promoção de profissionais, como também ao trabalho flexível, ergonomia e mudança de atitudes nas organizações, reforçando que no campo da formação e da aprendizagem, essas práticas devem garantir que os mais velhos não sejam desprivilegiados no treinamento e no desenvolvimento de carreira, e que as práticas de retenção devem preservar as experiências acumuladas dos profissionais mais velhos (CEPELLOS; TONELLI, 2017). 
$\mathrm{Na}$ direção oposta ao que pretendem as práticas de gestão de idade, algumas condutas reforçam o ageísmo na esfera organizacional, que pode ser entendido como:

[...] um conjunto de atitudes negativas ou positivas frente ao envelhecimento, valorizando ou desvalorizando a força de trabalho dos mais velhos, favorecendo ou desfavorecendo a sua inclusão/exclusão e permanência no mercado de trabalho. A discriminação quanto aos trabalhadores mais velhos, pode abranger desde a sua não contratação até a sua dispensa, especialmente quando a organização precisa reduzir seu quadro de funcionários (FRANÇA et al., 2017, pp.766-767).

Com a inversão da pirâmide demográfica, devido ao aumento progressivo no número de pessoas idosas, a longevidade pode ser considerada um ganho para toda a sociedade brasileira. No entanto, o bônus demográfico não foi efetivamente aproveitado, gerando uma situação em que a População Economicamente Ativa (PEA) do país, em breve, não suportará o sistema previdenciário, caso medidas não sejam tomadas por parte do governo no que diz respeito às políticas públicas direcionadas aos trabalhadores, mercado de trabalho e a organização deste. Entender a contribuição do envelhecimento ativo e da gestão da idade como subsídios de análise da longevidade no mercado de trabalho e enfrentamento ao ageísmo pode ser de fundamental importância, pois se acredita que esses conceitos poderão apoiar tal análise.

Para isso, considera-se a redefinição do conceito de envelhecimento ativo estabelecida pela Organização Mundial da Saúde (OMS), em 2015, em seu documento "Envelhecimento Ativo: um marco político em resposta à revolução da longevidade", onde este está pautado em quatro pilares, quais sejam: saúde, aprendizagem ao longo da vida, participação e segurança/proteção. Esse conceito envolve um "[...] processo de otimização de oportunidades para a saúde, a aprendizagem ao longo da vida, a participação e a segurança para melhorar a qualidade de vida à medida que as pessoas envelhecem" (ILC BRASIL, 2015, p. 42).

Ao se pensar o envelhecimento ativo aliado às práticas de gestão da idade, pensa-se no processo de construção/concepção e análise do ambiente laboral possibilitando maior longevidade no mercado de trabalho, sem que este seja desgastante, penoso ou insalubre. Ou seja, estas seriam ferramentas apropriadas às organizações, auxiliando no desenvolvimento econômico e produtividade desejados, sendo possível o desenvolvimento do indivíduo, que, ao educar/capacitar-se, valorizará a si próprio, na mesma lógica em que se valoriza o capital. Fazendo com que o trabalho seja melhor entendido como uma forma central de representação social de quem "SE É" enquanto indivíduo perante a sociedade.

Assim, objetivou-se com este estudo conhecer e analisar a história de vida laboral de uma pessoa idosa de 95 anos, que ainda se encontra ativa no mercado de trabalho formal, desenvolvendo a mesma atividade, pelas Instituições de Ensino Superior pelas quais passou, 
sejam estas, de caráter público ou privado.

O estudo se justifica pela trajetória laboral desta pessoa no mercado de trabalho, que está associada aos principais desafios colocados pela transição demográfica, quais sejam, a diminuição de mão de obra devido ao envelhecimento da população, a aposentadoria de indivíduos que ainda estariam aptos à continuar trabalhando, ou mesmo a não reinserção ou reabsorção destes em outras atividades ou na mesma, após a aposentadoria. Tal cenário laboral, se entendido como de baixa produção e crescimento econômico, pode tornar instável a economia no que diz respeito à sustentação da seguridade social e da produção de capital, um dos principais temas econômicos em discussão. Além do aspecto econômico, torna-se necessário quebrar paradigmas relacionados ao fato de que o envelhecimento traz consigo a ideia do "ser inútil", que "não serve mais", e que "não contribui" para a sociedade, dando origem a situações de ageísmo.

\section{O CAMINHO PERCORRIDO}

O presente estudo pode ser caracterizado como sendo do tipo descritivo exploratório, contrapondo a teoria e as situações do cotidiano (MICHEL, 2009). O método utilizado foi do tipo história de vida, com abordagem qualitativa, o que, não impede o surgimento de questões a serem reafirmadas por estudos qualitativos ou ainda quantitativos, futuramente, pois estudiosos já assumem posicionamento contra a existência da dicotomia e incompatibilidade entre estudos quantitativos e qualitativos (SOUZA; KERBAUY, 2017).

Deve haver, o entendimento que o qualitativo e o quantitativo se complementam e podem ser utilizados em conjunto nas pesquisas, possibilitando melhor contribuição para compreender fenômenos investigados, que cada vez mais se apresentam de diferentes maneiras (SOUZA; KERBAUY, 2017).

O método de história de vida, aqui utilizado, foi guiado por entrevista semiestruturada, junto ao sujeito participante deste estudo, uma pessoa idosa de 95 anos, escolhida intencionalmente pelas pesquisadoras, por estas terem o conhecimento de sua trajetória no mercado laboral, ou seja, ela ainda se encontra no mercado de trabalho formal, desenvolvendo a mesma atividade, em sua terceira organização. A escolha por esse método, é reforçada quando se percebe que a história de vida é um instrumento privilegiado para análise e interpretação, na medida em que incorpora experiências subjetivas mescladas com contextos sociais (ARAúJO et al., 2016). 
Este método tem por objetivo acessar uma realidade que ultrapasse o narrador. É ainda, a oportunidade de dar voz ao indivíduo que narra sua história, e que por vezes pode ter vivenciado seu discurso calado ou teve pouca oportunidade de expor seu ponto de vista sobre determinado assunto (SILVA et al., 2007). A história de vida devolve a palavra aos silenciosos e aos esquecidos da história e projeta uma iluminação particular ao social, ela tira a palavra dos lugares de silêncio e rechaçam um ponto de vista enquadrado em sistemas de pensamento exclusivos, redutores e totalitários (ARAÚJO et al., 2016).

Reforçando a importância desse método nos estudos qualitativos que procuram investigar temas por vezes considerados subjetivos, Perazzo (2015, p.130), afirma que:

\begin{abstract}
Assim, as Narrativas Orais de História de Vida constituem-se em um método para se trabalhar com o passado dos indivíduos, com o cotidiano e com as micro experiências sociais. Mas também é um método que nos permite compreender como as pessoas pensam, porque fazem ou fizeram suas escolhas na vida, que posição social assumiram. Por isso, é um método que nos permite compreender as subjetividades. E dessa forma, nos permite trazer para a ciência as dimensões dos sentidos, dos sentimentos e das mentalidades, que antes eram apenas dos domínios dos relatos literários e das crônicas (PERAZZO, 2015, p.130).
\end{abstract}

O local de estudo foi a cidade de Viçosa, localizada, na Zona da Mata do estado de Minas Gerais, que possui como estratégia de desenvolvimento econômico a presença de Instituições de Ensino Superior (IES), públicas e privadas, e demais instituições de ensino, e os diversos setores de serviços que a elas atendem, assim como à população que direta ou indiretamente estão ligadas às mesmas.

Também foram consultados livros, artigos, dissertações e teses que versassem sobre o tema, disponíveis em bases tais como SciELO, LILACS, Google Acadêmico, bibliotecas on line ou institucionais. A narrativa foi transcrita, analisada e discutida a luz da teoria sobre o tema, trazendo a história como ciência do acontecido e do acontecimento, para o diálogo com a história contada pelo próprio sujeito do estudo. Reforça-se ainda que a partir dos dados da entrevista, foi realizada análise, percorrendo as etapas de classificação/categorização, codificação, análise e comparação das falas com a literatura.

O participante foi informado sobre o objetivo do estudo e assinou o Termo de Consentimento Livre e Esclarecido (TCLE), atendendo aos princípios éticos inerentes à pesquisa dessa natureza e à resolução do Conselho Nacional de Saúde, CNS 466/2012 (BRASIL, 2012(b)). O projeto foi aprovado pelo Comitê de Ética em Pesquisa com Seres Humanos da Universidade Federal de Viçosa (CEP/UFV), por meio do parecer consubstanciado número 2.165.936. 


\section{RESULTADOS E DISCUSSÕES: O CASO DE HEFESTO}

O cenário acerca do envelhecimento da população brasileira e o seu impacto tanto para as organizações de trabalho quanto para a População Economicamente Ativa (PEA), suscita atenção de estudiosos, pois o Brasil ao contrário dos países desenvolvidos envelheceu antes de enriquecer, o que traz consequências para a saúde, economia, política, educação, qualidade de vida e outras variáveis relacionadas ao cotidiano não apenas da pessoa idosa, mas também de suas famílias, comunidade e Estado, sugerindo uma atenção urgente por parte de todos os envolvidos.

Assim, fez-se uso do método da história de vida, guiada por entrevista semiestruturada, para atender ao objetivo proposto neste estudo, qual seja, o de conhecer e analisar a história de vida laboral de uma pessoa idosa de 95 anos, que se encontra ativa no mercado de trabalho formal, desenvolvendo a mesma atividade, nas Instituições de Ensino Superior pelas quais passou, seja de caráter público ou privado, acreditando que as informações por ela repassadas serão de grande importância para se pensar variáveis que se qualifiquem como importantes para estruturação de futuros planos de retenção de trabalhadores experientes, bem como de capacitação e qualificação ao longo da vida laboral, para as organizações de trabalho.

O recorte da narrativa foi apresentado de forma a garantir o sigilo acordado com o participante. Para isto, foi a ele dado o nome de Hefesto, que na mitologia grega representava o deus do fogo, dos metais e da metalurgia. Sua figura também estava associada ao trabalho, pois foi um grande forjador e joalheiro. Hefesto era visto como o deus mais feio da mitologia grega e ainda, tinha uma deficiência era coxo (manco). Isso causou repugnância em sua mãe que o rejeitou desde o nascimento. Se fizermos uma analogia entre a figura de Hefesto com a pessoa idosa e o mundo do trabalho, vemos que estas por vezes são discriminadas por sua idade, pois ainda se cultua o jovem em suas várias dimensões, fazendo com que elas sejam descaradas ou colocadas de lado nos ambientes laborais (DIANA, 2018).

Hefesto tem 95 anos de idade, recém completados, nasceu no ano de 1923, na capital do estado de Minas Gerais, órfão de pai e mãe, foi morar em uma instituição que abrigava menores de idade nesta situação. É do sexo masculino, viúvo, tem oito filhos (05 homens e 03 mulheres). Tem ensino fundamental incompleto, trabalha como técnico de laboratório, mais especificamente na área de patologia animal, desde os seus 18 anos, quando saiu da instituição em que morava. Ao sair da referida instituição, foi convidado a trabalhar junto ao curso de medicina veterinária de uma Instituição de Ensino Superior Federal, mesmo não tendo formação/habilitação técnica. 
Hefesto destaca que todo seu conhecimento adveio da prática do dia a dia e de pequenos cursos e orientações dadas pelos professores com os quais trabalhou e trabalha, ou mesmo por parte dos fornecedores de equipamentos que usou e usa nos laboratórios.

\begin{abstract}
"Ó, eu comecei a estudar depois parei, eu casei novo, família foi aumentando, aumentando, aí ao invés de eu estudar à noite eu fui trabalhar. Eu saía da universidade, e eu ia pra uma instituição filantrópica, eu saía de lá 11h [23h] e corria pra pegar o bonde. Nessa época a gente andava de bonde né. Aí eu chegava em casa meia noite e tanto, chegava e olhava os filhos pra saber se tava vivo. Eu tive 08 filhos, cinco homens e três mulheres. Aí não deu pra mim, a família foi crescendo, foi crescendo, aí eu falei, eu tenho é que trabalhar. $E$ como saía cinco horas [17h] da universidade e pegava às sete horas [19h] nessa instituição, e saía 11 horas [23h], não dava pra estudar. Eu até tinha umas aulas, mas era coisa corriqueira, saber nome de vidro, de coisas de laboratório tal, porque quando eu era interno eu era auxiliar de enfermagem, mas não sabia bem as vidraria, né, e quando chegou no laboratório eu tinha que ficar com esse conhecimento. Porque isso tudo aqui [aponta para os vidros de reagentes que possui no laboratório], a gente tinha que preparar e punha tudo aí. Mas hoje já tá modificado, eles põe tudo junto, você já compra pronto, antes a gente tinha que fazer tudo. Quando chega um equipamento novo é só me explicar né, como era o funcionamento, aí depois ia praticando, aprendendo mesmo" (Hefesto, 95 anos).
\end{abstract}

Tal fato vai contra o que autores como Ilmarinem (2012), Fontoura e Piccinini (2012) e França (2011), afirmam. Pois de acordo com esses autores o processo de educação é um marco que as pessoas adquirem no início de suas vidas, influenciando mesmo no desenvolvimento e enfrentamento, por exemplo, de doenças, como as crônico-degenerativas, tal como o Alzheimer.

Além disso, Ilmarinem (2012) salienta que trabalhadores mais velhos estão aptos à aquisição de novos conhecimentos, uma vez que a aprendizagem não depende da idade, mas sim do processo de aprendizagem que varia de acordo com a idade, devendo ser utilizadas estratégias de aprendizagem e didáticas adequadas.

Ainda neste mesmo caminho, quando se pensa a relação grau de escolaridade e mercado de trabalho França (2011, p. 56) diz que:

Para garantir a empregabilidade, é preciso melhorar o nível educacional, aprender a linguagem do mundo digital, manter competências, habilidades e estar permanentemente atualizado em face das mudanças do mercado de trabalho (FRANÇA, 2011, p. 56).

Assim se vê a importância da capacitação ao longo da vida dos indivíduos. Quando a Organização Mundial da Saúde (OMS) traz como um de seus quatro pilares para o envelhecimento ativo, o aprendizado ao longo da vida, isso fica mais evidenciado na trajetória da discussão sobre o envelhecimento e a velhice. Além disso, é preciso considerar que a empregabilidade dos mais velhos não depende apenas da intenção dos trabalhadores de acessarem educação e atualização, mas da disponibilidade e criação de empregos flexíveis, pensados e elaborados de forma que valorizem o capital humano das organizações, levando-se 
em consideração as demandas e necessidades dos trabalhadores ao longo de seu percurso laboral (ILC BRASIL, 2015).

Como dito anteriormente Hefesto, começou a trabalhar formalmente como técnico de laboratório em patologia, em uma Instituição Pública de Ensino Superior na capital do estado de Minas Gerais, na área de medicina veterinária, no ano de 1941, desenvolvendo ali suas atividades até sua primeira aposentadoria em 1977.

Já aposentado, foi procurado por professores de outra Instituição de Ensino Superior Federal, situada no interior do estado de Minas Gerais e que eram egressos da Instituição em que Hefesto trabalhara para que ele viesse trabalhar nesta, ajudando-os principalmente na organização e estruturação da área de patologia, mais especificamente do laboratório.

Apesar de ainda não ser considerado uma pessoa idosa, se tomarmos o marco temporal do que hoje traz o Estatuto do Idoso em seu Art. 1, ao definir o idoso como aquele indivíduo que tem 60 anos ou mais (BRASIL, 2012(a)), pois em 1977, Hefesto tinha 54 anos, percebe-se que pelo tempo de serviço trabalhado e de contribuição, 36 anos, ele já reunia as condições para estar aposentado.

No entanto, apesar disto, não foi considerado por aqueles que conheciam seu trabalho, como um indivíduo incapaz ou inútil, com conhecimento ultrapassado, apenas pelo fato de ser uma pessoa idosa e aposentada, como geralmente acontece, dando destaque a uma situação de ageísmo, ou seja, o preconceito contra a pessoa idosa.

"[...] Aí tem gente que é daqui, gente que era da veterinária de lá, mas que é daqui, e eu aposentado lá e eles foram lá atrás de mim, falaram 'nós sabemos do seu trabalho e tal e a veterinária vai voltar aqui, será que você não podia dar uma mão?', aí eu falei, eu dô uai. Aí eu vim e fui ficando até hoje" (Hefesto, 95 anos).

Cepellos (2013) afirma que uma das causas de fomento ao ageísmo também nas organizações de trabalho, está no fato de as sociedades ocidentais cultuarem o novo, o jovem. O que se observou no caso de Hefesto, é a situação inversa, ou seja, a confiabilidade que deram ao seu conhecimento acumulado durante os anos em que trabalhou na Instituição.

Carvalho (2009) ressalta ainda que uma das dificuldades de a pessoa idosa permanecer trabalhando ou mesmo conseguir uma (re)colocação no mercado de trabalho após sua aposentadoria está dada na relação negativa que se faz entre o avanço da idade e a produtividade dos indivíduos. Essa é outra forma de reforço ao ageísmo, uma vez que em seus estudos, Fontoura e Piccinini (2012) afirmam não haver consenso, na literatura, quanto à queda de produtividade dos trabalhadores mais velhos, e que ao se pensar esta questão, não se deve partir apenas dos aspectos econômicos, mas também aspectos tais como, a experiência 
adquirida, os conhecimentos acumulados ao longo de uma vida e as habilidades aperfeiçoadas.

IImarinem (2012, p.2) reforça tal aspecto quando afirma:

\begin{abstract}
Os trabalhadores mais velhos podem adquirir novos conhecimentos. A aprendizagem não depende da idade, mas o processo de aprendizagem muda com a idade. [...] $\mathrm{Na}$ aprendizagem ao longo da vida, devem ser utilizadas estratégias de aprendizagem e didáticas adequadas. Em suma, o envelhecimento torna os trabalhadores mais velhos melhores e mais fortes do que antes, em muitos aspetos. Por conseguinte, a participação ativa na vida profissional é um importante fator positivo no envelhecimento ativo. Cada geração tem os seus próprios pontos fortes e debilidades; os pontos fortes dos trabalhadores mais velhos devem ser melhor identificados e aproveitados, de modo a tornarem-se ativos valiosos em cada local de trabalho (ILMARINEM, 2012, p.2).
\end{abstract}

Desta forma, quando se pensa em uma organização que se preocupa com a gestão da idade, e o seu papel ao relacionar o envelhecimento e trabalho, com reflexos na qualidade dos postos de trabalho ofertados e no desempenho dos trabalhadores mais velhos, tais elementos se colocam como de fundamental importância.

Mediante o referido convite, o senhor Hefesto aceita vir trabalhar na instituição, mudandose com a família da capital para o interior de Minas Gerais, dando prosseguimento às suas atividades como laboratorista na área de patologia, nesta nova instituição, do ano de 1981 à 1993, sendo o motivo de rescisão, a aposentadoria por idade, pois em 1993 já estava com 69 anos.

"Eu sei que em 1993, né, eles já tavam querendo me mandar embora, por causa da idade. [...] Mas eu ajudei muita gente fazendo material, eu preparava os material pros professores que iam estudar nos Estados Unidos, com as doenças que eles queriam. Eles iam fazer $\mathrm{PhD}$., eu acho né, é assim que fala?! E aí eu fiquei conhecendo muita gente famosa da área de patologia dos Estados Unidos, mas também da Argentina" (Hefesto, 95 anos).

Após a segunda aposentadoria, o senhor Hefesto então se muda com a família para o estado do Espírito Santo, para morar perto de um de seus filhos, permanecendo por lá até o ano de 2002, quando novamente é convidado por uma Instituição de Ensino Superior, agora de ordem privada, localizada na mesma cidade de seu último trabalho, para voltar ao mercado de trabalho formal, novamente para ajudar na estruturação e organização do curso de medicina veterinária que a referida instituição estava criando.

Nesta época, Hefesto, estava com 78 anos, por acreditar que ainda poderia contribuir com a instituição, utilizando de seu conhecimento construído durante tantos anos, assim como percebendo a importância que o trabalho tinha em sua vida, não apenas econômico, mas também social, aceita o convite e retorna à cidade, e às Minas Gerais, deixando o estado do Espirito Santo.

O trabalho, por vezes é fonte de garantia de independência, liberdade e autonomia para 
as pessoas idosas, e de acordo com Carvalho (2009) não apenas em âmbito econômico, como também para o exercício mental, identidade pessoal, exercício de cidadania, e aspectos de sociabilidade, visto que é uma oportunidade de relacionar-se com o próximo, diminuindo a rejeição social construída e vivida por elas.

Reforçando estas colocações encontradas na literatura, Hefesto, reafirma ao ser questionado "o por quê?" de continuar trabalhando até essa idade, mesmo já tendo se aposentado em duas ocasiões:

"O que eu vou ficar fazendo dentro de casa, arrastando chinelo, ahhh, eu não levo jeito pra isso não. E sabe, eu ainda ajudo um filho meu com dinheiro, ele tem problema, está perdendo a visão e também cuido do que mora comigo, ele tem diabetes, aí preciso ir com ele no médico e tomar conta das coisas" (Hefesto, 95 anos).

Sua colocação reforça não só o papel que o trabalho assume em sua vida social e mental, mas também econômica e do papel do cuidado. Este por sua vez, aparece de forma invertida, se considerarmos que quem deveria receber cuidados pela idade, seria Hefesto, e não seu filho. Isso demonstra que é necessária a quebra de paradigma e de estigma de que a chegada e a vivência da velhice é algo ruim, com o indivíduo passando de um "SER" que precisa de cuidados e inútil, para um "SER" que pode ser ativo e que tem responsabilidade para com os seus. O que se deve lembrar é que assim como outras etapas da vida, a velhice possui as suas peculiaridades e é composta por indivíduos cada vez mais heterogêneos.

Carvalho (2009) reafirma ainda que para pessoas idosas o trabalho pode apresentar diferentes dimensões significativas, como por exemplo, a de se manter financeiramente, auxiliar ou mesmo ser o maior responsável pelo orçamento familiar.

Uma nova etapa laboral formal se inicia. Na atual instituição, Hefesto já está há 16 anos (desde o ano de 2002). Seu registro é em carteira, desenvolvendo atividades em período integral (8 às $11 \mathrm{~h}$ e 14 às 18h), com atividades, que de acordo com o próprio, requerem exigências tanto mentais quanto físicas, de sua parte, afirmando que nunca se sentiu incapaz para a realização de seu trabalho ou mesmo que tenha passado por situações de preconceito devido a sua idade, pelas organizações por onde passou.

Mesmo diante deste cenário, ao ser questionado se percebia práticas de gestão da idade nestas Instituições, Hefesto, disse que não.

Assim também, Hefesto diz que em dados momentos, tem sim autonomia sobre seu trabalho no que diz respeito à necessidade de se ausentar do ambiente de trabalho, como por exemplo, para viagens ou idas ao médico, ou mesmo quanto ao seu horário de entrada e saída do trabalho. 
"Mas o Evaldo aí, que é o diretor geral, fala aí, eu quero é a presença dele né, e eu toda vida fui bom funcionário, quando eu tenho que sair, é só falar, quando eu vou em algum médico, ele 'não, não tem problema'. Aqui é de $8 \mathrm{~h}$ às $11 \mathrm{~h}$ e de $2 \mathrm{~h}$ [14h] às $18 \mathrm{~h}$, às vezes eu saio mais cedo" (Hefesto, 95 anos).

Tal fato foi levantado, pois, o que se vê na literatura, são casos de organizações que reforçam, mediante seus processos seletivos, a prioridade por pessoas jovens ou mesmo o incentivo por aposentadoria dos trabalhadores mais velhos, não investindo em práticas de gestão da idade, por acreditarem que trabalhadores mais velhos, proporcionam custos e gastos.

Mas a partir da fala de Hefesto que relata certa autonomia quanto ao seu trabalho, podendo em alguns momentos dispor de certa flexibilidade, percebe-se que a Instituição onde trabalha atualmente, pode até não ter formalmente um plano de gestão da idade, mas que já apresenta ações voltadas para tal.

Ilmarinem (2012) destaca que ao se pensar a gestão da idade nas organizações alguns objetivos devem ser priorizados, um deles, são as formas de trabalho compatíveis com a idade, onde se encaixariam políticas de flexibilização do trabalho, o que poderá oportunizar melhor qualidade de vida aos trabalhadores mais velhos, assim como equalizar as oportunidades em todas as gerações. Esse autor reforça ainda que quanto às ações de gestão da idade:

\footnotetext{
Os trabalhadores são mais responsáveis pela sua saúde e a sua competência, e ao empregador cabe uma maior responsabilidade pela empresa e a organização do trabalho. O conceito de promoção baseia-se, pois, na cooperação entre o empregador e o empregado: juntos podem criar um melhor equilíbrio no local de trabalho e reforçar a capacidade de trabalho (ILMARINEM, 2012, p. 5).
}

Assim também, Cepellos (2013) destaca que uma das possibilidades de se reter o trabalhador mais velho na instituição é oferecer a possibilidade de trabalhar de forma flexível, a fim de permitir que ele realize as atividades pessoais e familiares. Prática esta, que pode ser identificada na fala do entrevistado.

Outra questão identificada durante entrevista em que Hefesto relata sua história de vida laboral, e que reflete uma possível ação de gestão da idade, por parte da instituição em que trabalha, diz respeito ao processo de intergeracionalidade no ambiente e organização de trabalho, ou seja, a troca/compartilhamento de conhecimentos entre trabalhadores jovens e mais velhos. Hefesto, que exerce suas atividades de técnico de laboratório normalmente, tem passado pelo processo de treinar outro colaborador que o ajuda:

"Eu tenho um colega que trabalha comigo né, agora eu tô deixando mais pra ele, então, ele vai fazendo algumas coisas, porque antigamente a gente tinha que preparar os corantes tudo, hoje já é mais fácil, às vezes você já compra o corante, porque antigamente você tinha tantas técnicas. E desde lá da UFMG, entrava um, aí eu ensinava ele, né. $E$ assim ia, todo lugar, as três universidades, e eram mais novo. E se às vezes a gente errava 
alguma coisa, eles questionavam como é que eles faz [se referindo à pesquisadores da área e à teoria existente], então eu falava 'vamo vê na tioria mesmo como é que era, e era assim'. E eu aprendi mais foi com os meus chefes né, na época [se referindo à quando começou a trabalhar na área] eu não sabia nada e só tinha eles na época, na época a veterinária quase não tinha funcionário. Sempre o que eu pude ajudar eu ajudei. Porque às vezes eu falo 'ah, isso aqui parece que não tá assim e tal', aí eles falam 'vão fazer outra técnica e tal'. A vantagem deles é porque a coisa tá mudada né, então sai mais rápido e a gente às vezes, antigamente se vai fazer uma técnica e sai muito mais demorado do que hoje, então hoje sai muito mais rápido" (Hefesto, 95 anos).

Essa atitude, de intergeracionalidade, entre Hefesto e o novo colaborador, é visto na literatura, como uma das possíveis ações de gestão da idade que podem contribuir com a Gestão de Recursos Humanos (GRH) a se adaptar ao processo de envelhecimento da mão de obra, em que o conhecimento adquirido pelos sujeitos, ao longo de sua vida laboral, é compartilhado com aqueles que estão entrando/chegando às organizações.

Carvalho (2009) afirma que as características singulares acumuladas na trajetória de vida pelas pessoas idosas, podem favorecer o ambiente organizacional saudável, propiciando compartilhamento de saberes, com saldo positivo tanto para o trabalhador mais velho, que se sentirá valorizado pela organização, quanto para esta, que terá uma pessoa que conhece efetivamente as atividades desenvolvidas no dia a dia, compartilhando seu conhecimento. Sendo possível ainda que os trabalhadores mais novos aprendam com os mais velhos e que a produtividade melhore, devido a essa interação entre ambos.

Cepellos (2013) citando pesquisas desenvolvidas na Austrália e no Reino Unido, reforça tal situação quando afirma que:

A gestão de uma força de trabalho envelhecida requer consciência sobre as relações que
se estabelecem entre trabalhadores de diferentes idades e mostra também a importância
de se gerenciar as relações entre grupos de idade no ambiente organizacional. Sendo
possível observar alguns benefícios quando a empresa investe em uma equipe com
diferentes faixas etárias, como a possibilidade de orientação e aumento da produção.
Nestes casos, pessoas mais velhas podem transferir suas experiências para as mais
jovens e estas podem ensinar a nova tecnologia aos mais velhos, dado que os mais jovens
possuem maiores noções de informática (CEPELLOS, 2013, p. 42-43).

Algumas empresas já identificaram o potencial do trabalhador idoso no sentido de ser detentor de experiência, os quais representam sua identidade, uma vez que conhecem os detalhes dos serviços. Além disso, os funcionários mais jovens interpretam a contratação ou a retenção de pessoas idosas por parte das organizações como fator positivo, também para si mesmos, pois se sentem menos ameaçados pela possibilidade de serem descartados com o avanço da idade.

Outro fator que deve ser considerado quanto às práticas de gestão da idade, está relacionado às condições do ambiente de trabalho e suas principais implicações, questões 
importantes quando se pensa o processo de envelhecimento no mercado de trabalho, sendo questionado à Hefesto se ele recebia algum tipo de adicional de insalubridade ou de periculosidade, obtendo-se o relato:

"É... antigamente eles pagavam, eu andei recebendo, mas depois acabou. É ocê vê, se não tem inalação de formol aqui o dia inteiro, que você mexe com formol, e lá na anatomia também, e lá é ainda pior, porque tem muito, e aqui a gente mexe com o que vem nos vidros, e a gente mexe com formol em quase todas as peças" (Hefesto, 95 anos).

Percebe-se diante desta fala que há certo descontentamento por parte de Hefesto no que diz respeito às suas condições de ambiente de trabalho, uma vez que ele identifica possíveis fontes de perigo à sua saúde e também daqueles que frequentam o laboratório em que trabalha e ainda em outros dentro da instituição, e que podem estar passando despercebidas aos olhos dos responsáveis pelo setor de gestão de pessoas. Por isso, ouvir quem trabalha diretamente nos ambientes de trabalho, é importante para conhecer as exigências e possíveis demandas dos locais, assim como faz parte dos objetivos da ergonomia, ou seja, construir, junto a quem desenvolve e vivencia as atividades de trabalho, um ambiente cada vez mais seguro e saudável àqueles que ali estão, proporcionando adequada saúde, segurança e qualidade de vida no trabalho.

Fato a ser destacado aqui, é que em um dos encontros com Hefesto para realização da entrevista, ele estava desenvolvendo uma de suas atividades, qual seja a preparação de lâminas para detecção de possíveis doenças, a partir de tecidos retirados por autópsias ou necropsias, e em nenhum momento ele fez uso de Equipamentos de Proteção Individual (EPIs), tais como luvas, máscaras, óculos de proteção, dentre outros.

A importância da interação indivíduo versus ambiente de trabalho é reforçada ainda por Ilmarinem (2012), quando este toma por base a teoria da "Casa-Modelo "capacidade para o trabalho6'”, afirmando que:

\begin{abstract}
Atendendo a que numerosos problemas de saúde estão relacionados com a profissão, os riscos para a saúde associados ao trabalho devem ser identificados e prevenidos no local de trabalho ( $4 .^{\circ}$ andar). As fortes interações entre a saúde e o trabalho exigem uma colaboração ativa entre os especialistas em matéria de saúde e segurança no trabalho, os empregadores e os empregados (ILMARINEM, 2012, p. 5).
\end{abstract}

Assim, ainda querendo reforçar tal relação indivíduo versus ambiente de trabalho, pensando na proposição de variáveis quanto à qualidade de vida neste ambiente, foi perguntado

\footnotetext{
${ }^{6}$ A Casa-Modelo "capacidade de trabalho", descreve as diferentes dimensões com impacto na capacidade de trabalho humano. Esta capacidade consiste no equilíbrio entre o emprego e os recursos individuais, e vai além do local de trabalho, considerando que para o equilíbrio no desenvolvimento das atividades deve-se levar em conta também a família e a comunidade envolvente (ILMARINEM, 2012).
} 
à Hefesto, dentre as atividades de trabalho que realizou ou mesmo continua realizando, o que gostaria de melhorar ou mesmo mudar:

\begin{abstract}
"Agora ultimamente que arranjaram as coisas, porque antigamente não tinha, então a gente começou a ganhar insalubridade, pra mim era isso. Hoje as técnicas tão aparecendo, muitas coisas diferentes, sabe, porque antigamente, era mais trabalhoso, hoje não, hoje eu tenho aparelhos que ajuda bem a gente, sabe, antigamente era uma dificuldade" (Hefesto, 95 anos).
\end{abstract}

Novamente a questão da insalubridade é mencionada por Hefesto. Durante a fala deste, pode-se perceber uma importância mais acentuada dada ao econômico quando da relação construída pelo indivíduo entre a insalubridade e a forma como esta é retratada pela GRH, do que propriamente expor uma preocupação com sua saúde, segurança e qualidade de vida. Tal fato pode estar relacionado à importância econômica que o trabalho assume para as pessoas idosas, pois como afirma Carvalho (2009, p. 5), "para elas o trabalho alcança dimensões significativas, além de manter-se financeiramente ou auxiliar no orçamento familiar". E como já dito anteriormente, Hefesto menciona ajudar financeiramente um de seus filhos e cuidar da saúde do que mora com ele, fazendo com que, essa "renda extra", seja importante na administração de seu cotidiano.

Outra forma de valorização do indivíduo no ambiente de trabalho, diz respeito ao seu reconhecimento enquanto trabalhador. Hefesto relatou em sua narrativa, por diferentes momentos, sua satisfação ao receber homenagens por parte de alunos, egressos e das instituições pelas quais passou e está vinculado. Sendo em sua opinião, a que mais lhe emocionou, a que recebeu, prestes a completar 90 anos de idade, no ano de 2013, por parte das Universidades Federais de Minas Gerais (UFMG) e de Viçosa (UFV), pelo Conselho Regional de Medicina Veterinária de Minas Gerais (CRMV/MG) e pela União de Ensino Superior de Viçosa (UNIVIÇOSA), onde as referidas IES e o CRMV/MG condecoraram Hefesto, por sua importância no segmento educacional como técnico de laboratório.

A valorização do trabalhador, em especial do trabalhador mais velho, de acordo com Dejours (1999) configura um espaço onde o indivíduo busca sua autorrealização e identidade no campo social, visto que necessita do olhar e do julgamento do outro, implicando na necessidade de reconhecimento.

Também foi considerado importante para o presente estudo, identificar a percepção do entrevistado quanto ao processo de envelhecimento, questionando-o, por exemplo, sobre o que é ser velho ou uma pessoa idosa, em sua própria concepção.

"Ah, é [pausa], a gente mais novo tem mais disposição, né [risos] a idade vai chegando, mas, eu sinto que eu faço a mesma coisa de quando eu era mais novo, mais tem certa 
coisa, igual subi escada, os meus fio se eu subo escada xinga, né. Não posso subir escada, ah mas eu falo 'eu quero ver como é que tá a situação lá, eu que quero ver, né ocês não, a casa é minha e tal'. Eu entro lá no forro, ponho duas escadas assim [faz o gesto demonstrando com as mãos, tentando exemplificar como faz uso das escadas para chegar ao forro da sua casa], e entro no forro, por causa da instalação de luz, de água né, aí eu tenho que ver [risos]. É porque uma vez eles fizeram um andaime lá, que tava fazendo uma parede, e eu subi, e foi e o andaime quebrou, e eu disci e quebrei o pé, mas isso podia acontecer com qualquer um, novo... Ser velho então é não querer parar, tá sempre querendo fazer as coisas, e continuar fazendo, porque se ocê acomodar, eu acho que... [não conclui o pensamento]" (Hefesto, 95 anos).

Percebe-se que Hefesto também faz relação do "SER" uma pessoa idosa com as atividades que ela conseguiria desenvolver em seu dia a dia, o que pode-se levar também para o mundo das organizações em que a pessoa idosa é avaliada e julgada pelas atividades que consegue desenvolver e também por sua produtividade. Afinal, Cepellos (2013) afirma que a idade é um tema relevante nas organizações, pois o modo como os indivíduos experienciam o trabalho e a forma como estes se relacionam com essas experiências representam uma das preocupações da teoria organizacional.

Fineman (2011) ainda afirma que a idade pode representar diferentes marcadores de indicação social, de posição de status, e mesmo em que momento o indivíduo está em seu curso de vida. Além disso, a idade geralmente é definidora das condutas/atitudes/ações desejáveis a um indivíduo perante a sociedade à qual está inserido, submetendo-o às normas sociais.

Após relatar o que era ser uma pessoa idosa para ele, foi questionado à Hefesto, se ele se sentia de tal forma.

\footnotetext{
"Se eu sinto? Ah, mas é os meus filhos que não deixam eu fazer as coisas sabe, o problema é esse, mas foi como eu disse, eu sinto que eu faço a mesma coisa de quando eu era mais novo" (Hefesto, 95 anos).
}

Outro ponto importante quanto à gestão de recursos humanos, diz respeito ao preconceito gerado nas organizações de trabalho, quanto aos trabalhadores idosos, o ageísmo, seja por parte das próprias organizações, ou mesmo pelos colaboradores. No entanto, esta prática é inadmissível e vai contra o que preconiza o Estatuto do Idoso, que em seu Art. 26, assegura às pessoas idosas o direito de exercer uma atividade profissional em um ambiente saudável e seguro, com especial atenção às suas condições físicas, intelectuais e psíquicas para o desenvolvimento do trabalho produtivo (BRASIL, 2012(a)).

Hefesto, no entanto afirma não ter sentido ou vivenciado situações de preconceito pelas organizações por onde passou e ainda está trabalhando. Sendo este preconceito sentido mais pelas pessoas que conhece e convive em seu dia a dia, fora da instituição do que em seu ambiente de trabalho. 
“Não, eu encontro com uns colegas que falam 'ué, cê já aposentou, mas tá trabalhando?', eu falô, 'ué eu tô', eu não posso ficar parado não uai. Ainda mais depois que eu fiquei viúvo, ainda [risos] eu faço tudo que eu posso fazer, eu faço. Eu por exemplo, eu falei 'eu não vou parar', eu tô com saúde, então eu perdi a esposa, tal, então, eu tenho os filhos, tem que dar força pra ajudar a criar. Eu ajudava eles. Igual, tem um que ele tá quase cego e eu ajudo ele e o outro que tá comigo, que é diabético, ele tá com sessenta e poucos anos, aí que é mais complicado, tem que levar ao médico, e tudo, arranjar pessoa pra levar. Tem um que eu ajudo em dinheiro também, dô certa quantia pra ele, pra ajudar, ele ficou quase cego, tá fazendo tratamento" (Hefesto, 95 anos).

Aqui, percebe-se a dimensão da importância do trabalho na vida dos indivíduos, principalmente para as pessoas idosas, pois conforme argumentam Roque e Sousa (2016) há diversos fatores individuais, sociais e ambientais, que influenciam no trabalho, mas as necessidades que motivam o desenvolvimento de atividades produtivas na velhice, vão além das materiais, são também simbólicas.

Estar satisfeito com sua vida laboral, desempenhando atividades que lhe proporcionem bem-estar e que sejam fonte de motivação para permanecer no mercado de trabalho, depende também de como o ambiente de trabalho está organizado. Fontoura e Piccinini (2012) corroboram tal questão ao lembrarem que os indivíduos estão sim susceptíveis às perdas decorrentes do processo de envelhecimento, tais como declínio da força muscular, dificuldade de manter a postura e o equilíbrio e redução da visão e capacidade auditiva, dentre outros.

No entanto, essas perdas que são comuns à esse processo, podem ser amenizadas/corrigidas por adaptações nos espaços de trabalho, podendo contribuir para que trabalhadores mais velhos sigam trabalhando ou mesmo atuando na diminuição dos efeitos negativos da organização do trabalho na saúde do trabalhador. Além do espaço físico, deve-se dar atenção às relações interpessoais no ambiente de trabalho, priorizando um ambiente igualitário e saudável, evitando-se assim a ocorrência de ageísmo.

Assim também, é de responsabilidade do setor de gestão de pessoas e da diretoria conscientizar gerentes e demais funcionários da importância do trabalho desenvolvido por profissionais mais velhos e com mais tempo de experiência, além de combater as préconcepções atribuídas a este grupo geracional (FONTOURA e PICCININI, 2012).

Quanto a essas questões, Hefesto deixa transparecer que possui um bom relacionamento com as pessoas com quem trabalha e também com os estudantes que frequentam e fazem uso do laboratório. Mas que identifica demandas e necessidades por equipamentos que seriam necessários para melhorar o desempenho de suas atividades, até mesmo devido à experiência vivenciada nas outras instituições pelas quais passou. 
tô muito bem no meio deles, sabe. E do local, sempre muda alguma coisa, às vezes igual aqui, por exemplo, aqui tá precisando mesmo de uma câmara fria pra guardar animais, e tal, então tá tudo nas congelação ali, porque lá na UFMG tem a câmara [fria], aqui também eu acho que tem [se referindo à UFV], tem porque quando eu tive lá, tinha. Agora aqui é que não tem, você vê que tem quatro ou cinco congelador aí, quê vê, vem cá... [me leva até os congeladores e me mostra cada um, com seus conteúdos]" (Hefesto, 95 anos).

De fundamental importância para se pensar/elaborar ações e práticas de gestão de pessoas relacionadas ao envelhecimento ativo no ambiente de trabalho, é dar voz à pessoa idosa, que ainda se encontra no mercado de trabalho, seja formal ou informal, e identificar o que a motivou a permanecer ou retornar a este. IImarinem (2012) reafirma tal importância quando diz que a maneira mais fácil de promover o envelhecimento ativo no ambiente de trabalho é identificar novas necessidades e formas de redefinir o trabalho levando em consideração a opinião dos trabalhadores mais velhos, questionando-os como é que gostariam de mudar e melhorar o seu emprego e atividade.

\begin{abstract}
"Ah, que eu acho que se eu ficar em casa, eu acho que eu adoeço, porque eu quero é movimentar. Porque você até movimenta em casa, mas não é, toda hora, todo dia, e aqui não, eu tô no meio dos alunos e tal, né. Hummm, esse negócio de ficar arrastando chinelo dentro de casa, Deus me livre, Deus que me permita que não deixa eu ficar assim" (Hefesto, 95 anos).
\end{abstract}

Apesar de em sua fala Hefesto não ter diretamente exposto os motivos que o fazem ainda estar trabalhando, pode-se perceber que indiretamente, eles estão relacionados ao fato de se sentir útil e ativo, manter relacionamentos com as pessoas, estar em sociedade, se sentir apto para o desenvolvimento de suas atividades, e porque não, se sentir reconhecido pelo trabalho que faz.

Confirmando tais aspectos Carvalho (2009) afirma que o trabalho confere uma identidade predominante de trabalhador e não de aposentado, ou seja, um indivíduo que já não tem mais serventia para a sociedade e para o mercado. Fato este que também pode estar relacionado ao status de provedor, em oposição à situação de isolamento e segregação, mesmo dentro de suas famílias. Constituindo-se como forma de socialização, manutenção de poder e aumento da renda familiar, o que lhes confere certa autonomia, independência e liberdade.

Outra questão que deve ser abordada, diz respeito ao atendimento, por parte das organizações, das demandas/necessidades identificadas pelos trabalhadores, incluindo os mais velhos. Estas podem ser por equipamentos, ferramentas, ou mesmo por cursos de capacitação/treinamento.

"Principalmente quando chegava material novo né. Aí o vendedor vinha, explicava a gente, e a gente já ia tocando, né. E aí eles procuram atender [se referindo aos equipamentos e condições dos locais de trabalho, por exemplo, a necessidade de maior ventilação e da câmara fria]. Eu já tô achando aqui pequeno, aqui pra nós tá pequeno, tá tudo mesmo 
tumultuado" (Hefesto, 95 anos).

Mas ao ser questionado se a instituição the procurava para saber se suas demandas/necessidades relacionadas ao desenvolvimento das atividades e também as do ambiente de trabalho, estavam sendo atendidas, Hefesto reporta tal situação primeiramente aos materiais a serem utilizados nas preparações das lâminas. Em seguida lembra que quando chegam equipamentos novos, como um microscópio que havia chegado à pouco tempo, a instituição oferece treinamento por meio principalmente dos representantes e vendedores, e que depois, ia aperfeiçoando na prática, com ajuda de professores e sozinho mesmo.

O processo de envelhecimento de Hefesto parece não influenciar negativamente sua permanência no mercado de trabalho, indo contra ao que muitas instituições pregam, reforçando mesmo as questões de preconceito no ambiente de trabalho. Mas, sabe-se que seu exemplo, ainda é exceção, principalmente no Brasil, onde Carvalho (2009) afirma por meio de seus estudos haver indícios da necessidade de rever valores e processos na administração das organizações, especialmente, em relação à gestão de pessoas no que concerne à incorporação de políticas que contemplem a nova realidade demográfica mundial.

Hefesto acredita que:

\begin{abstract}
"Você tendo saúde, é que é o importante, porque é bom arranjar um servicinho, não ficar parado, não ficar arrastando chinelo dentro de casa não, dá umas volta. E eu já quase não conheço mais, porque já aposentaram [se referindo à outras pessoas idosas que, assim como ele estariam no mercado de trabalho]. Tem gente que aposentou até novo né. Igual hoje, hoje eu encontrei com um que aposentou de lá [UFV], e falou 'Aow, como é que é? Você tá sumido uai, cê tá trabalhando', eu falei 'uai eu trabalho', eu gosto de trabalhar, o que é que eu vou ficar fazendo em casa, arrastá chinelo? Então eu sou viúvo né, eu tenho que trabalhar" (Hefesto, 95 anos).
\end{abstract}

Por fim, foi perguntado à Hefesto, se ele já havia pensado em parar de trabalhar, ou mesmo até que idade gostaria de continuar trabalhando.

\footnotetext{
"Não tem quando, às vezes a gente cansa, aí eu falo que vou parar, mas passa. Mas até Deus deixar, minha filha de Curitiba fala, 'ah pai, vem pra cá', aí eu falo 'deixa eu trabalhar mais um bocado"' (Hefesto, 95 anos).
}

Estudos mostram que um dos motivos que levam a pessoa a se aposentar é a possibilidade de poder desfrutar de momentos até então ainda não vividos, tais como as viagens. Hefesto relata que gosta muito de viajar, e que em suas férias sempre viaja com um amigo, segundo ele 'um senhor de idade', seja de ônibus ou mesmo em cruzeiros marítimos, ou seja, ele consegue conciliar trabalho e lazer.

Bulla e Kaefer (2003) enfatizam tal situação, de saber relacionar trabalho, aposentaria e lazer, quando afirmam que a maneira como as pessoas idosas percebem o trabalho após 
aposentadoria pode ser ressaltada pela sua história de vida. Os processos de envelhecimento e de aposentadoria ocorrem de maneiras heterogêneas, apresentando múltiplas interfaces, que estão relacionadas às mudanças na vida social e no mundo do trabalho, à reorganização da vida familiar que se presencia em nossa sociedade atual, ao convívio dentro e fora do trabalho, à rotina laborativa, aos papéis sociais desempenhados, ao status do sujeito, ao modo de ser de cada um, aos projetos de vida, dentre outros.

Ao final, foi dada oportunidade de reforçar algo que Hefesto já havia relatado ou mesmo que gostaria de acrescentar quanto ao assunto.

\begin{abstract}
"A única coisa que tenho, é que todo esse pessoal que trabalhei com eles, fui muito bem tratado, né. O que eles pediam pra eu fazer eu fazia, se caso um dia acontece uma coisa, essa técnica não tá dando certo, vamo mudar e tal. E era assim. Não tenho nada a reclamar viu. Na verdade eu não tenho. A única coisa que a gente sabe, que eu sei, é que cê não é o que era, né. É a realidade. Às vezes eu quero pegar um negócio eu falo, deixa pra lá. E eu sempre gostei do que eu faço. Eu continuei trabalhando com a mesma coisa, porque se não, eu não sei se eu fosse pra outro lugar se eu ia dar certo, e aqui eu já tava carimbado aqui, então eu prefiro mesmo é trabalhar na minha parte mesmo. Porque lá em outro lugar, se bem que hoje já tá muito mudado as técnicas e tal, mas eu não vou fazer questão disso, se eu souber alguma coisa eu faço, se não, falo 'ó professor, não tô entendendo isso não' e não tem mais nada não" (Hefesto, 95 anos).
\end{abstract}

Também acrescentou que o que mais o deixou incomodado durante todos esses anos de vida laboral foi o não cumprimento do acordo quanto aos 'seus vencimentos' quando foi trabalhar na segunda instituição (uma universidade federal), pois lhe prometeram um valor, o mesmo recebido na época em que trabalhava na capital. No entanto, o valor pago foi menor.

Assim, percebendo-se a importância de dar voz a pessoa idosa, considerando as suas percepções quanto ao processo de envelhecimento no mercado de trabalho, no caso Hefesto, mesmo não sendo identificada uma política formal de gestão da idade pelas organizações pelas quais passou e ainda está, é possível sistematizar importantes variáveis de apoio a esta, a partir das falas deste e também de estudos realizados por Fontoura e Piccinini (2012) e Ilmarinem (2012) acerca dos objetivos e desafios da gestão da idade, sendo as principais: flexibilização do trabalho; relações intergeracionais; reconhecimento e valorização da contribuição pelo trabalho desenvolvido e do conhecimento adquirido por parte da pessoa idosa; importância da capacitação/treinamento e aprendizado constantes ao longo da vida; o não fomento ao ageísmo dentro das organizações.

Desta forma, ao apresentar estudos que retratem histórias como a de Hefesto, acreditase que haverá maior conscientização, de que o envelhecimento é uma conquista significativa, quando se foca na ampliação da capacidade da pessoa idosa em contribuir com a sociedade e garantir a empregabilidade do trabalhador maduro (a partir de 50 anos), em condições de 
igualdade de oportunidades e de recursos. Sendo necessário refletir acerca da valorização da pessoa idosa em nosso meio social, pois esta questão se coloca como desafio que requer respostas urgentes, pois ficou evidente nesta pesquisa que os fatores que as motivam a permanecer no trabalho estão relacionados principalmente, à manutenção de sua vida e saúde mental, social e econômica, recebendo reconhecimento no ambiente profissional, familiar, assim como a valorização da sociedade. Dessa forma, eles permanecem inseridos no contexto social e sentem-se úteis e capazes, superando o estigma de que a velhice seja a etapa da vida relacionada ao processo de finitude e inutilidade.

\section{CONSIDERAÇÕES FINAIS}

Apesar de já ser percebida a preocupação com a questão da transição demográfica e seu consequente processo de envelhecimento da população, por parte, principalmente da academia, ainda são poucos os estudos voltados especificamente para o entendimento do processo de envelhecimento no mercado de trabalho e suas consequências. Nesta perspectiva, ouvir a pessoa idosa sobre este contexto é fundamental.

Com o aumento da longevidade as pessoas querem continuar ativas, fazendo parte do processo produtivo. Querem quebrar o estigma vinculado à velhice, de que esta seria apenas a etapa relacionada à finitude e inutilidade dos indivíduos.

O trabalho para a pessoa idosa, além de se constituir em principal fonte de renda, pode propiciar complemento essencial à aposentadoria, além de ser uma forma do indivíduo se manter útil, se ocupar e ser apontado como uma questão de dignidade e pertencimento social.

Deve-se assim entender que processo de envelhecimento não significa improdutividade e dependência. E que a aposentaria não é necessariamente sinônimo de afastamento definitivo do mercado de trabalho, que casos como o de Hefesto são ainda minoria e exceção, mas que podem se tornar cada vez mais recorrentes, devido principalmente, aos avanços na área da saúde e das tecnologias. Devendo o próprio indivíduo tomar a sua decisão, a partir de suas vivências e significados, se quer ou não permanecer ou reingressar no mercado de trabalho. Por outro lado, deve-se investir em políticas organizacionais e públicas a fim de combater qualquer tipo de preconceito nas organizações (ageísmo).

Sendo assim, com base no presente estudo, em que a história de vida de Hefesto foi o pano de fundo, pôde-se perceber um sentimento e vontade crescente por parte deste em dar seguimento a sua vida laboral, contribuindo não só para o mercado de trabalho, como também 
para um possível abrandamento da sobrecarga do sistema previdenciário.

Hefesto, reforça com seu exemplo que, as pessoas idosas, enquanto sujeitos de direito e deveres, por meio dos conhecimentos adquiridos ao longo de suas vidas, podem contribuir para com as organizações, que devem estar preparadas para oferecer-lhes um ambiente organizacional que estimule a produtividade, a intergeracionalidade, o reconhecimento pelo desenvolvimento de suas atividades e o aproveitamento de seu capital intelectual.

Diante da história de vida, ora retratada neste estudo, foi possível inferir também que o entendimento a respeito da realidade contemporânea trazida pelo envelhecimento populacional e suas implicações no mercado de trabalho, e sua relação com o afastamento pela aposentadoria ainda é muito incipiente se considerarmos a literatura brasileira de embasamento para essa área.

Neste cenário, pesquisas que abordem o tema na perspectiva apresentada se tornam fundamentais para o entendimento das questões ligadas ao envelhecimento populacional em aspectos mais amplos. Pois, compreendendo os diferentes significados assumidos pelo trabalho para os indivíduos, será possível entender historicamente como os indivíduos se colocam na sociedade, definem sua identidade e exprimem sua vida em família e sociedade.

Desta forma, fica a sugestão de que outros estudos sejam realizados focalizando essa temática, pois com pesquisas como essa, será possível evidenciar a influência que o trabalho exerce na qualidade de vida das pessoas idosas que optam por continuar trabalhando ou mesmo se reinserir no mercado depois da aposentadoria. Assim como mensurar a importância de variáveis tais como o aprendizado ao longo da vida, a ergonomia, o capital humano e a gestão da idade no processo de envelhecimento nas organizações de trabalho.

Sendo possível também, além de demonstrar quais os motivos que levam as pessoas idosas a esta permanência ou reinserção, vislumbrar outras opções que promovam bem-estar na velhice e que garantam o reconhecimento e a valorização delas.

\section{REFERÊNCIAS}

ARAÚJO, P.; MARTINS, E.; FERNANDES, R.; MENDES, F.; MAGALHÃES, C. O Método das Histórias de Vida na Investigação Qualitativa em Psicologia. Investigação Qualitativa em Saúde (Investigación Cualitativa em Salud), Atas CIAIQ, v. 2, 2016. Google

BRASIL. Legislação sobre o idoso: Lei no 10.741, de $1^{\circ}$ de outubro de 2003 (Estatuto do Idoso), e legislação correlata. $2^{a}$ ed. Brasília: Câmara dos Deputados, Coordenação Edições Câmara, 2012(a).

BRASIL. Ministério da Saúde. Conselho Nacional de Saúde. Resolução n 466, de 12 de dezembro de 2012. 2012(b). Disponível em: 
<http://bvsms.saude.gov.br/bvs/saudelegis/cns/2013/res0466_12_12_2012.html>. Acesso em: 15 nov. 2018.

BULLA, L. C.; KAEFER, C. O. Trabalho e aposentadoria: as repercussões sociais na vida do idoso aposentado. Revista Virtual Textos \& Contextos, n. 2, ano II, p. 1-8, dez., 2003.

CARVALHO, A. S. Gestão de pessoas e envelhecimento: sentido do trabalho para o idoso. In: ENCONTRO DA ANPAD, 33. São Paulo. Anais do... São Paulo: ANPAD, 2009. Disponível em: <http://www.anpad.org.br/diversos/trabalhos/EnANPAD/enanpad_2009/GPR/GPR3213.pdf>. Acesso em: 22 nov. 2018.

CENTRO INTERNACIONAL DE LONGEVIDADE DO BRASIL - ILC BRASIL. Envelhecimento Ativo: um marco político em resposta à revolução da longevidade. ILC BASIL. Rio de Janeiro, RJ. 2015. 119 p.

CEPELLOS, V. M. O Envelhecimento nas organizações: das percepções de gestores de recursos humanos às práticas de gestão da idade. São Paulo, 2013. 99p. Dissertação de Mestrado (Mestrado em Administração de Empresas), Fundação Getúlio Vargas, 2013.

CEPELLOS, V. M.; TONELLI, M. J. Envelhecimento profissional: percepções e práticas de gestão da Idade. Revista Alcance [Eletrônica], v. 24, n. 1, jan./mar., 2017. \$coosese Goggle

DEJOURS, C. Conferências brasileiras. Tradução de Ana Fonseca Reis; Revisão técnica de Maria Irene Stoco Betiol e Maria José Tonelli. São Paulo: Fundap: EASP/FGV, 1999.

DIANA, D. Hefesto. 2018. Disponível em: <https://www.todamateria.com.br/hefesto/>. Acesso em: 12 fev. 2019.

FINEMAN, S. Organizing age. Oxford: Oxford. 2011.

FONTOURA, D. dos S.; PICCININI, V. C. Envelhecimento populacional e gestão de pessoas: pesquisas internacionais e notas para o Brasil. XXXVI Encontro da Associação Nacional de Pós-Graduação e Pesquisa em Administração, Rio de Janeiro, 22 a 26 de setembro de 2012. Anais ... Disponível em: <http://www.anpad.org.br/admin/pdf/2012_GPR2116.pdf>. Acesso em: 11 nov. 2018.

FRANÇA, L. H. de F. P. O envelhecimento populacional e seu reflexo nas organizações: a importância da educação ao longo da vida. B. Téc. Senac: a R. Educ. Prof., Rio de Janeiro, v. 37, n. 2, p. 49-60, mai./ago., 2011.

FRANÇA, L. H. de F. P.; BRITO, A. da R. S.; VALENTINI, F.; MENEZES, I. V.; TORRES, C. V. Ageísmo no contexto organizacional: a percepção de trabalhadores brasileiros. Rev. Bras. Geriatr. Gerontol., Rio de Janeiro, v. 20, n. 6, pp. 765-777, 2017.

ILMARINEM, J. Promover o envelhecimento ativo no local de trabalho. Agência Europeia para a Segurança e Saúde no Trabalho. p. 1-9., 2012. Disponível em:

<https://osha.europa.eu/pt/tools-and-publications/publications/articles/promoting-active-ageingin-the-workplace>. Acesso em: 15 nov. 2018. Goggle

LAVILLE, A.; VOLKOFF, S. Envelhecimento e Trabalho. In: P. Falzon, Ergonomia. São Paulo: 
Blücher, 2007, p. 111-121.

MICHEL, M. H. Metodologia e pesquisa científica em ciências sociais. $2^{\mathrm{a}}$ ed. São Paulo: Atlas, 2009.

PERAZZO, P. F. Narrativas Orais de Histórias de Vida. Comunicação \& Inovação, PPGCOM/USCS, v. 16, n. 30, pp. 121-131, jan-abr., 2015. Scossese Goggle

PEREIRA, M. G. Transição demográfica e epidemiológica. In: PEREIRA, M. G. Epidemiologia teoria e prática. 8. ed. Rio de Janeiro: Guanabara Koogan, 2005. p. 157-185.

PINTO, A. M. G. L. R. S. Envelhecimento, trabalho e práticas de gestão de recursos humanos. Lisboa: 2015. 266p. Tese de Doutorado (Doutorado em Gestão e Desenvolvimento de Recursos Humanos), Instituto Universitário de Lisboa, 2015.

ROQUE, T. da G.; SOUSA, A. M. V. de. O idoso e o trabalho: caminhos para uma vida digna. XII Seminário Nacional: Demandas sociais e Políticas Públicas na Sociedade Contemporânea, II Mostra Nacional de Trabalhos Científicos, Santa Cruz do Sul, 19 a 20 de maio de 2016.

Anais do... Disponível em:

<https://online.unisc.br/acadnet/anais/index.php/snpp/article/viewFile/14574/3273>. Acesso em: 20 nov. 2018.

SILVA, A. P.; BARROS, C. R.; NOGUEIRA, M. L. M.; BARROS, V. A. de. "Conte-me sua história": reflexões sobre o método de História de Vida. Mosaico: estudos em psicologia, Belo Horizonte, v. I, n. 1, p. 25-35, 2007.

SOUZA, K. R.; KERBAUY, M. T. M. Abordagem quanti-qualitativa: superação da dicotomia quantitativa-qualitativa na pesquisa em educação. Educação e Filosofia, Uberlândia, v. 31, n. 61, p. 21-44, jan./abr. 2017. Scouses Goggle

WISNER, A. A inteligência no trabalho: textos selecionados de ergonomia. São Paulo: FUNDACENTRO, 1994. 191p. 